\title{
Report on the IVRDT Dissolution Instrument Qualification Survey
}

Geoffrey N. Grove

e-mail:Geoffrey.grove@gmail.com

SOTAX Corporation

68A Elm Street

Hopkinton, MA 01748

\section{ABSTRACT}

This report summarizes the results of the In Vitro Release and Dissolution Testing Focus Group (IVRDT) Dissolution Instrument Qualification Survey. The IVRDT is an AAPS Focus Group affiliated with the Analysis and Pharmaceutical Quality (APQ) section of AAPS. This was a web-based survey conducted during the fourth quarter of 2010. The goal was to collect an overview of dissolution instrument qualification practices in use today. The survey was written by the IVRDT committee and forwarded to all IVRDT focus group members. Questions in the survey cover PVT testing, USP and FDA recommended mechanical calibration, and vibration.

\section{INTRODUCTION}

\begin{abstract}
-he interpretation of the survey results and the assignment of statistical significance are not addressed in this report. Questions are grouped into sections and reported together to allow the reader to more quickly and clearly review the results. In total, 55 respondents participated in the survey. The full text of the questions is provided in the appendix. A full set of report results with all of the multiple choice question text is available upon request.
\end{abstract}

\section{PVT TESTING}

From the answers to Questions 1-4, we see that the majority of respondents (78.2\%) use the PVT tablet test for qualification, with $20 \%$ no longer using the PVT and fewer than $2 \%$ using other methods developed in-house.

Typically, respondents perform PVT every six months.

\section{The New PVT Testing Procedures}

The new PVT procedure gave $82.3 \%$ of the respondents new challenges with $47 \%$ of the respondents experiencing failures. Of the failures observed, about one-third of the respondents were unable to determine the cause. Of the $14.3 \%$ who were able to identify the cause of the failures:

1. Three found that media degassing was the root cause.

2. Two found issues with tablets.

3. One reported media and timing issues.

4. One reported an issue with the dissolution bath.

\section{Vibration}

Our survey found that a significant number of respondents $(45.3 \%)$ do not check for vibration. Perhaps this is due to the use of the PVT test to capture contributions from vibration and other experimental variables. Of those who do check for vibration, fewer than $25 \%$ use a quantitative device to take the measurement, and fewer than $12 \%$ have a specification. Two respondents $(3.6 \%$ of all survey participants) stated that the vibration

\section{Qualification Procedure}

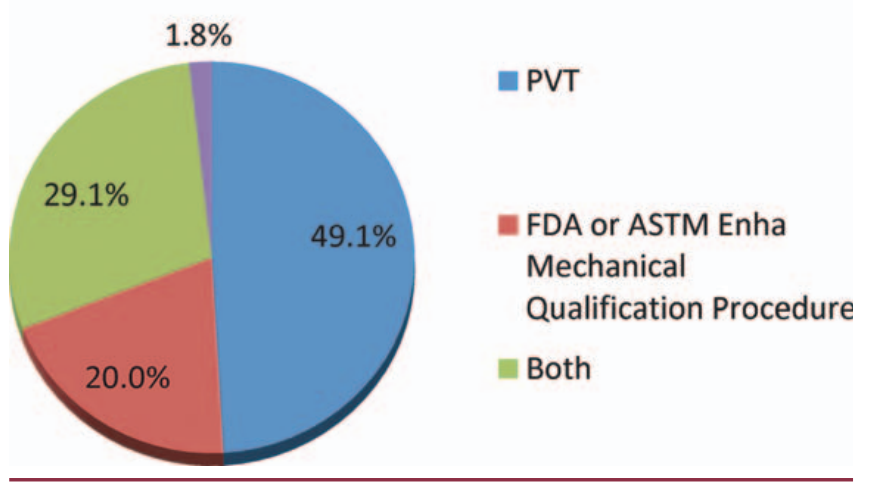

specification was 0.2-mm displacement, another respondent ( $1.8 \%$ of all survey participants) stated a 0.1 -mm displacement, and the rest (94.5\% of all survey participants) either use a meter without a specification or do not use a meter.

\section{Mechanical Qualification}

Looking to the future, $49.1 \%$ of respondents plan to switch to the FDA mechanical qualification procedure once it is official. Of the current customers using the FDA enhanced mechanical qualification, $20 \%$ (4 respondents) received

\begin{tabular}{|c|c|c|}
\hline \multicolumn{3}{|c|}{ How frequently is PVT performed? } \\
\hline Answer Options & Response Percent & Response Count \\
\hline Annually & $12.7 \%$ & 7 \\
\hline Semi-annually & $60.0 \%$ & 33 \\
\hline Quarterly & $3.6 \%$ & 2 \\
\hline At installation or major change & $3.6 \%$ & 2 \\
\hline Do not perform PVT & $18.2 \%$ & 10 \\
\hline \multirow[t]{3}{*}{ Other (please specify) } & $1.8 \%$ & 1 \\
\hline & answered question & 55 \\
\hline & skipped question & \\
\hline
\end{tabular}

Note: The "other" response stated twice a year, which is the same as semi-annually, so this response should be added to the semi-annual total. 
What have been your biggest challenges or concerns regarding the changes introduced for the USP PVTs? (select all that apply)

\begin{tabular}{l|cc|}
\hline Answer Options & Response Percent & Response Count \\
& & \\
N/A - We do not use the USP PVT & $13.7 \%$ & 7 \\
Passing Paddle Geometric Mean & $13.7 \%$ & 7 \\
Passing Basket Geometric Mean & $11.8 \%$ & 6 \\
Passing Paddle \%CV & $33.3 \%$ & 17 \\
Passing Basket \%CV & $19.6 \%$ & 10 \\
No Challenges & $41.2 \%$ & 21 \\
Other (please specify) & $3.9 \%$ & 2 \\
& answered question & $\mathbf{5 1}$ \\
& skipped question & $\mathbf{4}$ \\
\hline
\end{tabular}

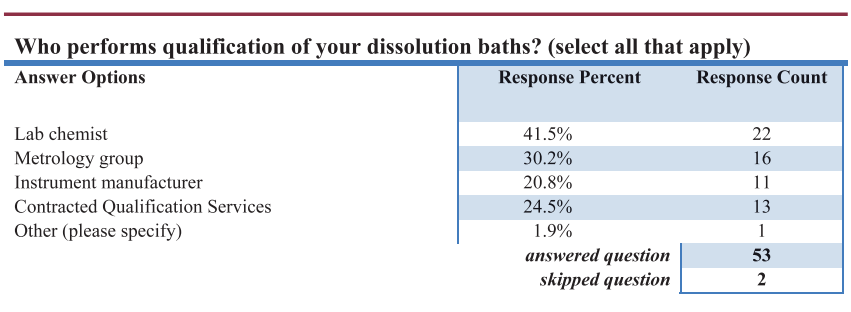

Note: A complete set of survey results is available upon request.

some questions from the FDA regarding its use. Approximately $61 \%$ of those using the mechanical qualification believe that it saves them time and money, and $59.6 \%$ believe that it will reduce the frequency or intensity of investigations.

The majority $(57.1 \%)$ of respondents rely on their vendors to supply quality vessels within specifications, while another $30.6 \%$ obtain a certificate with each vessel. A few (8.2\%) check these parameters in-house.

Performing a mechanical check twice a year was the most popular choice (59.6\%), with an annual qualification (25\%) coming in second. Some respondents claim to do checks more frequently, on a quarterly or even daily basis. Between lab chemists and the metrology group, $71.7 \%$ of qualifications are handled internally, while $45.3 \%$ are outsourced to contract services. This is over $100 \%$ because some company subdivisions may have outsourced staff working in-house, or because some choose to do the 6-month qualification and have the vendor perform the annual qualification.

Finally, the survey shows that vessel temperature, shaft height, and rpm are the most commonly checked parameters (each $>75 \%$ ), while verticality and wobble are only checked less than $30 \%$ of the time.

\section{APPENDIX}

Survey Questions:

1. What is your present procedure for qualification of USP dissolution apparatus 1 and 2 ?

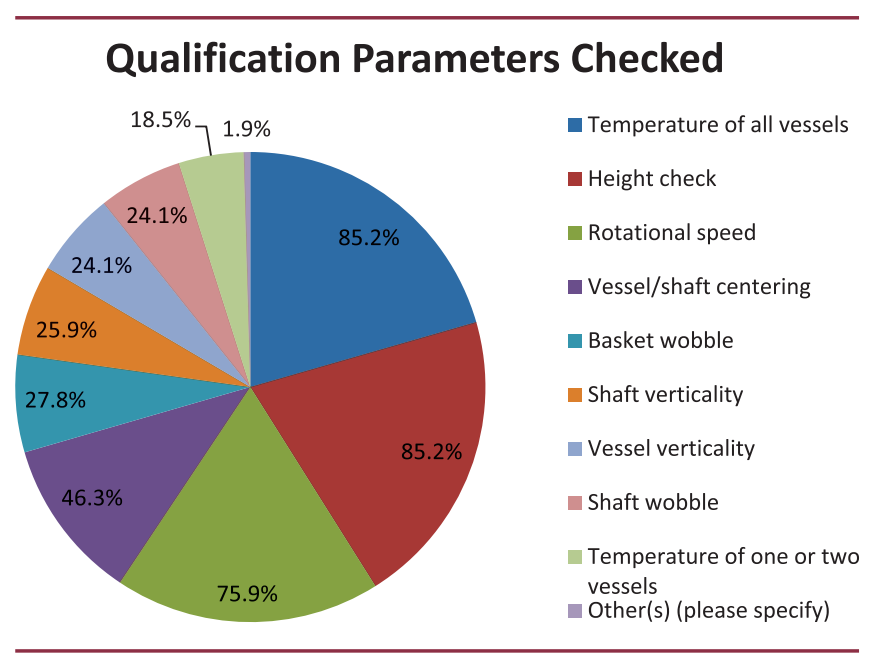

2. If you are performing PVT, how frequently?

3. What have been your biggest challenges or concerns regarding the changes introduced for the USP PVTs? (select all that apply)

4. If you have experienced PVT failures, were you able to identify an assignable cause?

5. Are you measuring vibration of the dissolution apparatus?

6. If you use a vibration meter, does your company have an established limit for vibration?

7. Do you plan to change (or have you already changed) the Enhanced Mechanical Qualification Procedure now that the FDA guidance is official?

8. If you or your company is using Enhanced Mechanical Qualification Procedure, has an FDA investigator ever questioned you or your company about its use?

9. Will or does Enhanced Mechanical Qualification Procedure save your company money, time, or other resources compared to PVT?

10. Do you think the adoption of the Enhanced Mechanical Qualification Procedure alone will decrease the number or intensity of investigations related to dissolution bath qualification?

11. In conformance with Enhanced Mechanical Qualification procedures, how do you verify the quality of your dissolution vessels?

12. How frequently are you performing the full set of mechanical checks (either USP or FDA)?

13. Who performs qualification of your dissolution baths? (select all that apply)

14. What instrument parameters do you check routinely prior to performing a dissolution test? (select all that apply) 